Bioética

\section{O DESENVOLVIMENTO CIENTÍFICO DA GENÉTICA E OS DIREITOS HUMANOS}

Em 1997, a Unesco emitiu a Declaração Universal do Genoma Humano e Direitos Humanos. Tal documento é de suma importância para a reflexão da prática médica atual sobre o desenvolvimento científico no campo da genética humana. Afirma que o genoma humano constitui a unidade fundamental dos seres humanos, que devem ser reconhecidos em sua dignidade e diversidade. Que todos têm direito ao respeito de sua dignidade e dos direitos referentes às suas características genéticas $\left(\right.$ art. $\left.1^{\circ}\right)$. Ressalta que o indivíduo não pode ser reduzido às suas características genéticas $\left(\right.$ art. $2^{\circ}$ ), e que genoma humano contém potencialidades humanas que são expressas diferentemente, de acordo com o ambiente natural e social de cada pessoa, incluindo seu estado de saúde, condições de vida, nutrição e educação. Ainda, que o genoma humano, em seu estado natural, não deve ser objeto de ganhos financeiros.

\section{Comentário}

Se os princípios da dignidade e do respeito à diversidade do ser humano não forem contemplados adequadamente, o reconhecimento de existência futura de doenças de caráter hereditário poderá resultar em práticas discriminatórias. Por exemplo, informações genéticas podem ser utilizadas contra candidatos a empregos e à filiação em sistemas de seguro de assistência à saúde. O professor Jean Bernard, primeiro presidente do Comitê Consultivo de Ética da França, sem revelar a fonte, afirma que diversas empresas têm obrigado que os candidatos a empregos apresentem seu grupo HLA (Human Leucocyte Antigens), grupo tissular revelador de tendências e predisposição ao aparecimento de moléstias de origem genética. Mediante tais testes, têm excluído potenciais futuros doentes de seus quadros. Nos EUA, encontram-se relatos de que uma escola privada de medicina recusou a inscrição de uma jovem de 20 anos, portadora de um gene relacionado a uma afecção renal, alegando possibilidade de futuro comprometimento de seu trabalho.
Por isso, entende-se que o avanço científico deva ser planejado e discutido democraticamente na sociedade, esclarecida de seus objetivos e conseqüências.

Paulo Antonio de Carvalho fortes Referências

I. Bernard J. La bioéthique. Paris: Flammarion; 1994. p.5I.

2. Mattei JF. Les droits de la vie. Paris: Odile Jacob; 1996. p.76.

3. UNESCO. The Universal Declaration on the Human Genome and Human Rights: from theory to practice. In: $29^{a}$ Sessão da Conferência Geral da UNESCO. November II 1997.

\section{Clínica Cirírgica INDICAÇÖES PARA 0 TRATAMENTO OPERATÓRIO DA OBESIDADE MÓRBIDA}

A obesidade mórbida é considerada uma doença epidêmica na América do Norte e em vários países do mundo, destacando-se como um problema de saúde pública. Esta doença é caracterizada por ser multifatorial, de origem genética e metabólica, agravada pela exposição a fenômenos ambientais, culturais, sociais e econômicos, associados a fatores demográficos (sexo, idade, raça) e ao sedentarismo.

$O$ índice aceito universalmente para a classificação da obesidade é o de massa corpórea (IMC) proposto por Quetelej, em 1835, e é expresso pelo peso em quilogramas do indivíduo dividido pelo quadrado da altura em metros. Tem como inconveniente não distinguir a massa gorda da magra, porém foi adotado em 1997 pela Organização Mundial da Saúde (OMS) como o índice de referência de medida para a obesidade. A OMS divide a obesidade em três níveis, sendo grau I com IMC entre 30 e $34,9 \mathrm{Kg} / \mathrm{m}^{2}$, grau II entre 35 e $39,9 \mathrm{Kg} / \mathrm{m}^{2}$ e grau III ou obesidade mórbida com IMC acima de $40 \mathrm{Kg} / \mathrm{m}^{2}$.

A classificação aceita pela Sociedade Americana de Cirurgia Bariátrica e pela Federação Internacional de Cirurgia da Obesidade divide a obesidade em seis níveis: obesidade pequena $\left(27\right.$ a $\left.30 \mathrm{Kg} / \mathrm{m}^{2}\right)$, obesidade moderada (30 a $\left.35 \mathrm{Kg} / \mathrm{m}^{2}\right)$, obesidade grave $\left(35 \mathrm{a} 40 \mathrm{Kg} / \mathrm{m}^{2}\right)$, obesidade mórbida $\left(40\right.$ a $\left.50 \mathrm{~kg} / \mathrm{m}^{2}\right)$, superobesidade (50 a $60 \mathrm{Kg} / \mathrm{m}^{2}$ ) e supersuperobesidade (maior de $60 \mathrm{Kg} / \mathrm{m}^{2}$ ).

A obesidade decorrente de doenças endócrinas deve ser tratada clinicamente (Síndrome de Cushing, hipotireoidismo). Cada doente deve ser avaliado por uma equipe multidisciplinar.

\section{Comentário}

As indicações para o tratamento operatório da obesidade, de acordo com as normas da Sociedade Brasileira de Cirurgia Bariátrica, são as seguintes:

1. Portadores de obesidade mórbida com IMC maior ou igual a $40 \mathrm{~kg} / \mathrm{m}^{2}$ registrado durante pelo menos dois anos. Devem apresentar insucesso em tratamentos conservadores realizados continuamente, de maneira séria e correta, também pelo período mínimo de dois anos;

2. Pacientes com IMC entre 35 e $39,9 \mathrm{Kg} / \mathrm{m}^{2}$, portadores de doenças crônicas desencadeadas ou agravadas pela obesidade.

\section{Carlos Roberto Puglia}

Referências

I. National Institutes of Health. Clinical guidelines on the identification, evaluation and treatment of owerweight and obesity in adults: the evidence report. Obes Res 1998; 6 (Suppl 2).

2. Garrido Jr AB. Situações especiais: tratamento da obesidade mórbida. In: Halpern A, Matos AFG, Suplicy HL, Mancini MC, Zanella MT, editores. Obesidade. São Paulo: Lemos Editorial; 2002. p.33l-40.

3. Leite MA, Valente DC. Tratamento cirúrgico da obesidade mórbida: indicações, seleção e preparo dos pacientes. Programa de AutoAvaliação. Bol Informativo Col Bras Cir 2003; 2(supl 3). Obesidade mórbida.

\section{Clínica Médica}

\section{ENDOCARDITE INFECCIOSA}

A endocardite infecciosa (El) possui um alto risco de morbidade e mortalidade. Depois da sepse urológica, pneumonia e sepse intra-abdominal é a síndrome infecciosa que mais ameaça a vida nos dias de hoje. Apresenta uma elevada incidência - 15.000 a 20.000 casos novos ao ano'. O seu prognóstico depende de um diagnóstico rápido, tratamento efetivo e um pronto reconhecimento de suas complicações. 
O diagnóstico dessa síndrome infecciosa, segundo a recente diretriz da Sociedade Européia de Cardiologia, é estabelecido (El definida) se, durante um episódio de infecção sistêmica, for demonstrado o acometimento do endocárdio e, em adição, a hemocultura for positiva ou DNA bacteriano for encontrado. Portanto, a El, dentro deste contexto, não deixa de ser um diagnóstico definido mesmo se a cultura for negativa. Para esta diretriz, o critério de Duke pode ser utilizado apenas em casos não muito claros ${ }^{2}$. Essa é uma abordagem diferente da estabelecida pela American Heart Association, que prioriza seguir estratégias diagnósticas para a El devido às diferentes formas de apresentação clínica, baseadas no critério de Duke, um método de alta sensibilidade e especificidade!.

O diagnóstico, segundo a Sociedade Européia de Cardiologia, é baseado em situações que levam a uma elevada suspeita clínica de El, com indicação urgente de avaliação ecocardiográica e possível admissão hospitalar, ou que direcionam a uma baixa suspeita clínica. Essas condições que conduzem ao diagnóstico de El são: I- a evidência de uma nova lesão valvar (sinal de regurgitação); 2- evento(s) embólico(s) de origem desconhecida (especialmente infarto cerebral ou renal); 3- sepse de origem desconhecida; 4- hematúria, glomerulonefrite e suspeita de infarto renal; 5- febre associada à presença de prótese cardíaca ou outra predisposição elevada para El, a uma nova arritmia ventricular ou distúrbio da condução, à primeira manifestação de ICC, à hemocultura positiva (se o microorganismo identificado for típico para valva nativa ou prótese valvar), às manifestações cutâneas (Osler, Janeway) ou oftálmicas (Roth), a infiltrados pulmonares multifocais ou com rápida evolução (El do coração direito), a um abscesso periférico (renal, esplênico, espinhal) de origem desconhecida, ou à recente intervenção diagnóstica e/ou terapêutica predisponente que pode resultar em significante bacteremia. Uma baixa suspeita clínica de El é a presença de febre na ausência dos sinais mencionados acima².

Segundo a American Heart Association, é recomendado o acompanhamento ecocardiográfico do paciente com diagnóstico de El após tratamento clínico. A importância dessa conduta está relacionada ao crescimento da vegetação cardíaca preexistente. Se houver um aumento, este achado poder significar risco maior de complicações, independente da sua evolução clínica (bacteremia persistente, piora ou não melhora de sinais e sintomas). Se evidenciar persistência da vegetação (59\% dos casos), na ausência de regurgitação valvar, grave, mesmo na presença de sintomas, esse achado não se correlaciona com complicações futuras.

\section{Comentário}

Talvez, para um médico recém-formado, seja mais prudente seguir o critério de Duke para o diagnóstico de El, visto que pode the faltar experiência clínica e, portanto, bom senso para afastar com certeza essa síndrome tão rica em diferentes formas de apresentação. Entretanto, para aquele médico que exerce a sua atividade por mais tempo, a orientação recomendada pela Sociedade Européia de Cardiologia talvez seja mais coerente por não limitar essa síndrome apenas a achados clínicos e ecocardiográficos e sim por acrescentar a esse contexto a experiência profissional e o senso crítico de cada um no exercício da medicina.

Patricia Gutierrez Daniela Calderaro Referências

Bruno Caramelli

I. Diagnosis and management of infective endocarditis and its complications. Circulation 1998; 98:2936-48.

2. Guidelines on Prevetion, Diagnosis and Treatment of Infective Endocarditis Executive Summary. Eur Heart I 2004; 25:267-76.

\section{Pediatria \\ DIABETES MELLITUS TIPO 1 E OS ANTICORPOS CONTRA ALBUMINA SÉRICA BOVINA}

$O$ processo de auto-imunidade envolvido no diabetes mellitus tipo I (DMI) é bem reconhecido, mas surgem questões ainda discutíveis sobre o papel de determinados antígenos na gênese desta auto-imunidade. $O$ trabalho de Santos et al. estudou 143 crianças recém-diagnosticadas de DMI comparadas a 107 crianças controle não aparentadas, pesquisando a presença de anticorpos contra albumina sérica bovina (BSA). Todas as crianças diabéticas eram positivas para BSA comparadas a 1,9\% dos controles $(p<0,00 I)$. As crianças diabéticas também apresentavam níveis de lgG mais elevados (55, I vs $17,8 \mathrm{ng} / \mathrm{mL}, \mathrm{p}<0,00 \mathrm{I}$ ). A duração do aleitamento materno era menor nas crianças diabéticas
(5,4 meses vs 7,6 meses), mas não havia diferença quanto à idade de exposição ao leite de vaca. A conclusão dos autores é que os níveis de anticorpos a BSA eram mais elevados nas crianças diabéticas, mas não pareciam depender nem da duração do aleitamento materno ou da idade de exposição ao leite de vaca nesta população.

\section{Comentário}

Já há aloum tempo tem sido tentada uma ligação entre aleitamento materno e diabetes mellitus tipo I, no sentido da proteção que o aleitamento materno podería acarretar em relação ao desenvolvimento de DMI. Como comentado em Editorial que acompanha o artigo de Santos et al., vários trabalhos têm detectado a presença de anticorpos a BSA, mas os resultados ainda são controversos. Os anticorpos para BSA não são específicos e podem ser encontrados em outras doenças auto-imunes como tireoidite ou artrite reumatóide. O trabalho de Santos et al. também não encontrou associação entre o HLA de classe Il que conferiria risco genético para DM e os níveis de anticorpos para BSA. A questão de por que os níveis de anticorpos contra BSA estariam elevados é intrigante: um estudo australiano mostra uma maior ingestão de leite de vaca em crianças com DM, comparadas aos controles, no período de 12 meses antecedendo a doença. Outra possibilidade seria um defeito na indução de tolerância às proteínas do leite de vaca. Como o leite de vaca é a primeira proteína alimentar estranha que as crianças ingerem, esta perda de tolerância seria expressa pelos anticorpos contra BSA. Outra idéia é relacionada à permeabilidade intestinal aumentada com relação às proteínas do leite de vaca, mas há poucos dados em suporte desta hipótese. Tomados em conjunto, os dados podem apontar para um fenômeno não diretamente ligado à patogênese do DMI, mas o assunto ainda não está encerrado e mais estudos são necessários e poderão contribuir para uma melhor compreensão da doença.

\section{Durval Damiani}

Referências

I. Pérez-Bravo F, Oyarzún A, Carrasco E, Albala C, Dorman JS, Santos JL. Duration of breast feeding and bovine serum albumin antibody levels in type I diabetes: a case-control study. Pediatr Diabetes 2003; 4:|57-6I.

2. Knip M. Cow's milk antibodies in patients with cewly diagnosed type I diabetes: primary or secondary? Pediatr Diabetes 2003; 4:I55-6. 